\title{
PRODUTOS NATURAIS COMO CANDIDATOS A FÁRMACOS ÚTEIS NO TRATAMENTO DO MAL DE ALZHEIMER
}

Cláudio Viegas Junior, Vanderlan da Silva Bolzani e Maysa Furlan

Instituto de Química, Universidade Estadual Paulista “Júlio de Mesquita Filho”, CP 355, 14801-970 Araraquara - SP

Carlos Alberto Manssour Fraga* e Eliezer J. Barreiro

Faculdade de Farmácia, Universidade Federal do Rio de Janeiro, CP 68006, 21941-590 Rio de Janeiro - RJ

Recebido em 28/7/03; aceito em 20/10/03; publicado na web em 27/05/04

NATURAL PRODUCTS AS CANDIDATES FOR USEFUL DRUGS IN THE TREATMENT OF ALZHEIMER'S DISEASE. Alzheimer's disease (AD) is a progressive neurodegenerative pathology with severe economic and social impact. There is currently no cure, although cholinesterase inhibitors provide effective temporary relief of symptoms in some patients. Nowadays drug research and development are based on the cholinergic hypothesis that supports the cognition improvement by regulation of the synthesis and release of acetylcholine in the brain. There are only four commercial medicines approved for treatment of AD and natural products have played an important role in the research for new acetylcholinesterase inhibitors.

Keywords: Alzheimer's disease; acetylcholinesterase; natural products.

\section{INTRODUÇÃO}

\section{A doença de Alzheimer: impacto social e fisiopatologia da doença}

A doença de Alzheimer (DA) é uma desordem neurodegenerativa, de grande impacto sócio-econômico, responsável por ca. 50-60\% do número total de casos de demência dentre pessoas acima dos $65 \operatorname{anos}^{1}$. Esta patologia afeta cerca de $1,5 \%$ da população em idade entre 65 69 anos, $21 \%$ entre $85-86$ e $39 \%$ acima dos 90 anos, acometendo aproximadamente 15 milhões de pessoas em todo o mundo.

Nos Estados Unidos, é considerada um dos principais problemas de saúde devido ao enorme impacto causado ao indivíduo, famílias, sistema de saúde e à sociedade como um todo, uma vez que metade dos pacientes são internados em instituições de saúde. O restante recebe tratamento em casa, envolvendo em seu cuidado, familiares, parentes e amigos. Invariavelmente, o acompanhamento do paciente traz um enorme stress emocional, psicológico e financeiro às famílias, uma vez que o tratamento é caro e o paciente perde gradualmente suas funções motoras e de aprendizado, passando a não reconhecer os familiares mais próximos ${ }^{2}$.

Cientistas estimam que cerca de 4 milhões de pessoas possuem esta doença e que sua incidência duplica a cada 5 anos, após os 65 anos de idade $^{2}$. Além disso, 4 milhões de americanos possuem 85 anos ou mais e, no país mais industrializado do mundo, este grupo etário é um dos segmentos da população que mais cresce, devendo atingir pelo menos 19 milhões de indivíduos no ano de 2050, dos quais metade poderá desenvolver alguma forma de $\mathrm{DA}^{2}$. Um estudo recente estima que o custo anual do tratamento de um paciente com DA leve é de U\$ $18.408,00$, U\$ 30.096,00 para DA moderada e U\$ 36.132,00 para um paciente com DA severa ${ }^{2}$.

O processo degenerativo progressivo das funções psicomotoras e cognitivas, descrito inicialmente pelo patologista alemão Alois Alzheimer em 1907, dura cerca de 8,5-10 anos, desde o aparecimento dos primeiros sintomas clínicos até a morte. As regiões cerebrais

*e-mail: cmfraga@pharma.ufrj.br, URL: http://www.farmacia.ufrj.br/lassbio associadas às funções mentais superiores, particularmente o córtex frontal e o hipocampo, são aquelas mais comprometidas pelas alterações bioquímicas decorrentes de $\mathrm{DA}^{1,3,4}$. Dentre as causas mais evidentes da gênese da doença estão a ocorrência de deposição extracelular de peptídeo $\beta$-amilóide (derivado do precursor amilóide de proteína - APP) em plaquetas senis e a formação errática de neurofibrilas intracelulares (contendo uma forma anormal, fosforilada, de uma proteína associada a microtúbulos - TAU) ${ }^{1,4}$. Todo este processo resulta em perda da função neuronal e dano sináptico, com subseqüente comprometimento da memória, da coordenação motora e do raciocínio, além de perda da capacidade cognitiva e demência.

Em nível celular, a DA está associada à redução das taxas de acetilcolina (ACh) no processo sináptico, diminuindo a neurotransmissão colinérgica cortical, além de outros neurotransmissores como noradrenalina, dopamina, serotonina, glutamato e substância $\mathrm{P}$ em menor extensão $0^{5,6}$. Estudos mais recentes demonstraram ocorrência de redução do número de receptores nicotínicos e muscarínicos $\left(\mathrm{M}_{2}\right)$ de $\mathrm{ACh}$, muitos dos quais localizados nas terminações colinérgicas pré-sinápticas, havendo preservação dos receptores muscarínicos $\left(\mathrm{M}_{1}\right.$ e $\left.\mathrm{M}_{2}\right)$ pós-sinápticos ${ }^{1,2}$.

\section{Biossíntese, hidrólise e função da acetilcolinesterase}

A acetilcolina é biossintetizada a partir da acetil-coenzima A (acetil-CoA) e colina por ação da enzima colina-acetiltransferase (Esquema 1$)^{7}$.

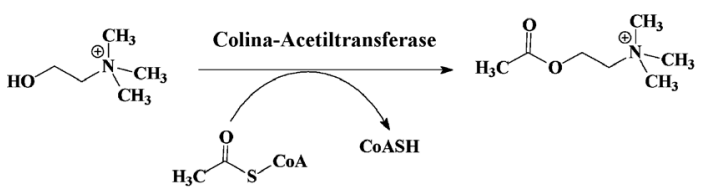

Esquema 1. Reação de biossíntese de acetilcolina $(A C h)$

Este neurotransmissor é encontrado no cérebro e nas junções neuromusculares, compondo parte do sistema nervoso parassimpático. 
Seus efeitos incluem a contração dos músculos lisos, dilatação dos vasos sanguíneos e regulação da taxa de batimentos cardíacos; no cérebro está envolvido nas sinapses associadas ao controle motor, memória e cognição ${ }^{7}$ Sua atividade e permanência na fenda sináptica são reguladas por hidrólise catalisada pela acetilcolinesterase (AChE), que regenera a colina, seu precursor. O sítio ativo da $\mathrm{AChE}$ é composto por uma tríade catalítica composta por resíduos de aminoácidos serina (Ser200), histidina (His-440) e glutamato (Glu-327) (Figura 1). O mecanismo de hidrólise de $\mathrm{AChE}$ envolve o ataque nucleofílico da serina ao carbono carbonílico da ACh, gerando um intermediário tetraédrico estabilizado por ligações de hidrogênio, o qual produz colina livre e serina acetilada. Ao final, a hidrólise do grupo acetila da serina pela água recupera o sítio catalítico da enzima ${ }^{8}$.

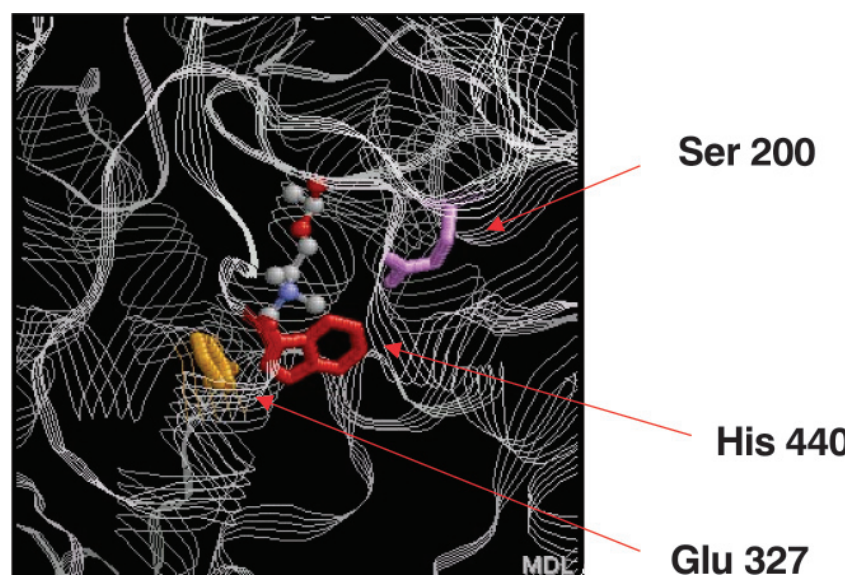

Figura 1. Visão do sítio ativo da AChE e dos resíduos de aminoácidos que constituem a tríade catalítica

\section{Terapia Colinomimética da doença de Alzheimer}

O fundamento da hipótese colinérgica está relacionado à capacidade de fármacos potencializadores da função colinérgica central induzirem melhora do perfil cognitivo e, também, de alguns efeitos comportamentais oriundos pela doença. Várias alternativas terapêuticas foram avaliadas no intuito de corrigir o déficit colinérgico em portadores de DA. Algumas estratégias inicialmente empregadas envolveram a utilização ou substituição de precursores de ACh, e.g. colina ou lecitina, as quais entretanto não se mostraram eficientes no incremento da atividade colinérgica central ${ }^{1}$. Outros estudos investigaram o uso de inibidores de acetilcolinesterase (AChE) que reduzam a hidrólise de $\mathrm{AChE}$ aumentando, conseqüentemente, seu tempo de vida-média, e.g. fisostigmina. Recentemente, têm sido exploradas abordagens terapêuticas envolvendo agonistas específicos de receptores muscarínicos $\left(\mathrm{M}_{1}\right)$ e nicotínicos ou antagonistas muscarínicos $\mathrm{M}_{2}{ }^{1,4}$. Os avanços obtidos na compreensão da evolução e das razões moleculares da gênese de DA têm demonstrado que o uso de inibidores de AChE deve ser a forma mais eficiente de controle da evolução da doença ${ }^{1,5,6,10,11}$.

Outra abordagem terapêutica para DA é o desenvolvimento de agonistas diretos de receptores muscarínicos pós-sinápticos $\mathrm{M}_{1}$ (Figura 2). A estimulação destes receptores demonstrou efeitos de aumento da cognição em animais. Entretanto, apesar dos esforços no desenvolvimento de ligantes agonistas de receptores $\mathrm{M}_{1}$, muitos dos compostos testados mostraram baixa seletividade, além de vários efeitos colaterais devidos à ativação de iso-receptores muscarínicos $\mathrm{M}_{3}$ nos intestinos, bexiga e pulmão (Figura 2). Agonistas de receptores $M_{1}$ não-seletivos podem, também, interagir com receptores $M_{4} \mathrm{e}$ $\mathrm{M}_{5}$ no SNC, com consequiências ainda desconhecidas ${ }^{12}$ (Figura 2).
Alternativamente, dados farmacológicos em modelos animais demonstraram que o bloqueio dos auto-receptores $\mathrm{M}_{2}$ pós-sinápticos (Figura 2) acarreta o aumento dos níveis de ACh, e a conseqüente melhora do déficit cognitivo. Entretanto, a despeito de um grande número de antagonistas $\mathrm{M}_{2}$ terem sido relatados, poucos mostraram seletividade frente a outros subtipos de receptores muscarínicos ${ }^{12}$.

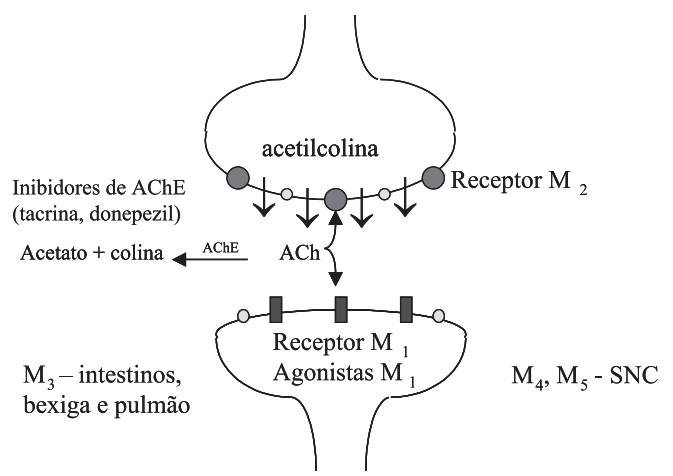

Figura 2. Visão esquemática da hipótese colinérgica e localização dos receptores muscarínicos. Adaptada da Ref. 12

A observação inicial de que os antagonistas muscarínicos tipo escopolamina produziam déficits na memória de curta duração levou à proposta de que o déficit colinérgico na DA era predominantemente de natureza muscarínica. Entretanto, este ponto de vista foi alterado por uma série de evidências, incluindo estudos autoradiográficos e histoquímicos de autópsia de tecido cerebral, além de estudos em imagens cerebrais em pacientes, que demonstraram a perda específica de receptores nicotínicos em maior extensão que de muscarínicos na DA ${ }^{10,13,14}$

Atualmente, existem muitas evidências indicando que substâncias moduladoras de receptores nicotínicos afetam o aprendizado e a memória. A nicotina e outros agonistas nicotínicos podem melhorar as funções cognitiva e psicomotora, enquanto que antagonistas nicotínicos causam deficiência na cognição. Além disso, a incidência da DA em fumantes é menor que em não-fumantes, o que pode se relacionar ao aumento dos níveis de expressão dos receptores nicotínicos da ACh (nAChRs) observados no cérebro de fumantes. Assim sendo, moduladores nicotínicos podem apresentar efeitos agudos e crônicos na função cognitiva, dentre os quais pode-se incluir a neuroproteção ${ }^{13}$.

Os receptores nicotínicos neuronais (nAChR) são expressos sob vários subtipos nos mamíferos, sendo que os subtipos $\alpha 4 \beta 2$ e $\alpha 7$ são os mais proeminentes e estão presentes em regiões pós-, pré-, peri e extrasinápticas. Os nAChR $\alpha 7$ exercem funções pouco diferenciadas daquelas dos subtipos $\alpha 4 \beta 2$, com maior permeabilidade para íons $\mathrm{Ca}^{++}$, dessensibilização muito mais rápida e diferente perfil farmacológico, o qual inclui ativação por colina $(\mathrm{Ch})$ e bloqueio pela $\alpha$-bungarotoxina (uma toxina de cobra) ${ }^{14}$. Devido a sua sensibilidade à $\mathrm{Ch}$, os receptores nicotínicos $\alpha 7$ podem ser quimicamente excitados mesmo após o agonista natural, i.e. ACh, ter sido hidrolisado pela AChE. Além disso, devido a sua alta permeabilidade a íons $\mathrm{Ca}^{++}$, a ativação dos receptores $\alpha 7$ pode produzir respostas metabotrópicas nas células excitadas, incluindo a liberação de transmissores controlada por $\mathrm{Ca}^{++}$e estimulação da transcripção genética e biossíntese protéica $^{10,13,14}$.

Modernamente, há duas estratégias principais sendo aplicadas para equilibrar o déficit colinérgico em portadores de DA: inibição da degradação da ACh e administração de agonistas de receptores nicotínicos ${ }^{10,13,14}$ (Figura 3). Os fármacos inibidores de acetilcolinesterase vêm sendo, atualmente, a alternativa terapêutica mais comu- 
mente empregada por apresentarem melhores resultados no controle da doença ${ }^{10}$ sem, entretanto, serem capazes de impedir sua progressão em nenhum de seus níveis ${ }^{13,14}$.

Vários agonistas de receptores nicotínicos encontram-se em fase de ensaios pré-clínicos e clínicos, embora já se saiba que seja relativamente difícil seu ajuste de dosagem; em níveis elevados, podem causar dessensibilização de nAChR em maior extensão que o aumento de sua ativação. Outros desafios, ainda insolúveis até o presente momento, consistem no transporte do fármaco até o receptor nicotínico-alvo no cérebro e o incremento da seletividade pelo subtipo de receptor específico ${ }^{13}$.

Os últimos avanços realizados no estudo dos receptores nicotínicos permitiram a melhor caracterização de alguns aspectos relacionados à sua fisiologia, bioquímica e expressão gênica, bem como sua efetiva participação nos eventos relacionados à DA. Adicionalmente, estes estudos com nAChR permitiram caracterizar uma nova estratégia possível para o tratamento de DA, através de sua modulação alostérica ${ }^{10,13,14}$. Moduladores alostéricos são substâncias que interagem com o receptor através de sítios de ligação distintos daqueles utilizados pela ACh e pelos agonistas e antagonistas nicotínicos ${ }^{14}$. Como DA está associada com a redução da neurotransmissão nicotínica, os moduladores alostéricos são potencializadores da atividade da ACh sobre os canais iônicos dos receptores nicotínicos. Estas propriedades deram origem a uma nova classe de ligantes de $\mathrm{nAChR}$, os ligantes potencializadores alostéricos (APL) $)^{10,14}$.

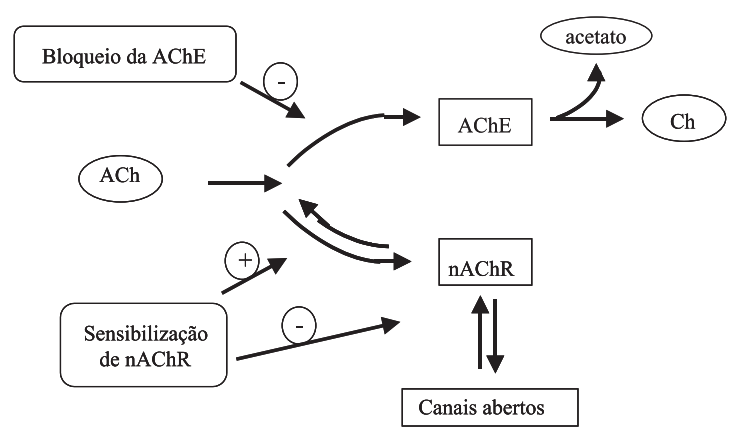

Figura 3. Resumo do processo e das formas de intervenção desde a liberação até a degradação da ACh. Adaptada da Ref. 10

\section{Fármacos comerciais para o tratamento da DA}

A tacrina (THA, Cognex $\left.{ }^{\circledR}, 1\right)$ foi o primeiro fármaco sintético aprovado pelo FDA ("Food and Drug Administration") nos Estados Unidos para uso terapêutico, demonstrando efeito moderado, mas significativo no alívio dos sintomas de DA de intensidade, média e leve. Entretanto, sua aplicação tem sido limitada devido aos sérios efeitos colaterais, como a hepatotoxicidade, que têm forçado os pacientes a descontinuarem o tratamento ${ }^{5}$. Além da tacrina, atualmente outros três fármacos estão sendo comercializados nos EUA e Europa: donepezil $\left(\mathbf{2}, \operatorname{Aricept}^{\circledR}\right)$, rivastigmina $\left(3\right.$, Exelon $\left.^{\circledR}\right)$ e, por último, a galantamina $\left(\mathbf{4}, \operatorname{Reminy}^{\circledR}\right)$. Dentre estes, as substâncias $\mathbf{1 ,} 2$ e 4 são inibidores reversíveis da $\mathrm{AChE}$, sendo que a galantamina (4) é um produto natural, recentemente aprovado pelo FDA, que está servindo de protótipo para desenvolvimento de novos fármacos anticolinesterásicos ${ }^{3,5}$.

\section{Busca por novos candidatos de origem natural para 0 tratamento da DA}

A diversidade estrutural dos IAChEs conhecidos e a possibilidade de se explorar modos de ação distintos têm estimulado o estudo fitoquímico de várias espécies vegetais e de microorganismos, que possam fornecer novos modelos de substâncias anticolinesterásicas. Neste sentido, várias exemplares da biodiversidade têm sido estudados em decorrência de sua utilização popular ou de dados etno-botânicos. Um dos exemplos mais difundidos como fitomedicamentos são os extratos de Ginkgo.

A Ginkgo biloba (Ginkgoaceae) é uma árvore fóssil utilizada há séculos na medicina tradicional chinesa para melhoria do estado de alerta. Hoje em dia, a ginkco é, talvez, o extrato vegetal mais difundido especificamente para aumento da função cognitiva, sendo seu uso prevalente especialmente na Europa onde, recentemente, o "German Bundesgesundheit Association" aprovou sua utilização para tratamento de demência ${ }^{15}$. A maioria das evidências sugere que a capacidade de aumento da função cognitiva está associada ao uso de um extrato padronizado, o EGb 761. A medida dos efeitos cognitivos vem sendo realizada em testes de atenção, aprendizado, memória de tempo-curto e tempo de reação e escolha, mas os resultados não são reprodutivos interpopulações. Além disso, muitos estudos estão publicados em periódicos de circulação restrita, o que dificulta o acesso às informações; na maior parte dos casos, os experimentos in vivo, tanto em animais como em humanos, restringem-se a pequeno número de indivíduos, o que compromete uma avaliação conclusiva e abrangente dos resultados ${ }^{15}$.

Alguns estudos utilizando pacientes tratados com o extrato padronizado de Ginkgo biloba e com placebo revelaram que os efeitos foram comparáveis aos obtidos com o donepezil (2), que atualmente é um dos fármacos de escolha para o tratamento da $\mathrm{DA}^{15}$. Aparentemente, muitos dos efeitos protetores do SNC associados ao uso crônico de extratos de Ginkgo estão relacionados à presença de constituintes terpênicos e flavonóides com propriedades antioxidantes e antiinflamatórias. Estas substâncias podem atuar de diferentes formas, contribuindo para a integridade do tecido neuronal: a) inibindo a atividade das enzimas superóxido-dismutase e monoamina-oxidase, que contribuem para a geração de radicais livres no cérebro e no corpo; b) seqüestrando radicais livres que poderiam causar dano aos neurônios e, conseqüentemente, retardar as mudanças associadas à idade no cérebro e c) reduzindo a liberação de ácido araquidônico, um co-produto tóxico do metabolismo lipídico, que aparece no cérebro logo após o episódio isquêmico ${ }^{15}$.

A necessidade de tornar mais objetivas e menos dispendiosas as pesquisas por constituintes químicos de plantas, animais e microorganismos levou ao desenvolvimento de numerosas técnicas de ensaios químicos e bioquímicos para monitoramento e seleção de extratos, frações de extratos e substâncias puras bio/farmacologicamente úteis. Quanto à busca de inibidores de $\mathrm{AChE}$, dois testes bioautográficos em cromatografia em camada delgada foram recentemente desenvolvidos ${ }^{16}$. Marston e colaboradores ${ }^{17}$ utilizaram um corante azóico para identificar a atividade da AChE sobre o acetato de 1-naftila; no outro caso, Rhee et al. ${ }^{18}$ preconizaram a utilização de 5,5'-ditiobis-(ácido 2-nitrobenzóico) (reagente de Ellmann) para a visualização da atividade enzimática. Aparentemente, o único inconveniente da utilização do reagente de Ellmann é o limite de detecção visual pois, em ambos os casos, formam-se halos de inibição brancos sobre placa corada de azul (teste de Marston et al. ${ }^{17}$ ) e amarelo (teste de Rhee et al. $)^{16}$.

Um estudo recente com plantas brasileiras ${ }^{19}$ utilizou o ensaio bioautográfico de Rhee et al. e o ensaio de Ellmann em microplaca $^{18,20}$, para identificar extratos que poderiam conter substâncias inibidoras da AChE. Foram estudados 58 extratos de 30 espécies de diversos gêneros vegetais, dos quais os autores consideraram os resultados de inibição maior ou igual a 50\% como critério de seleção para o fracionamento químico. A partir do trabalho de triagem, Paullinia cupana (guaraná), Amburana cearensis (cumaru) e Lippia 
sidoides foram as espécies que demonstraram os melhores resultados, inibindo de $65-100 \%$ da atividade enzimática, em ambos os bioensaios. No caso do guaraná, foi evidenciado um efeito positivo de incremento de memória após a administração aguda e crônica; o fracionamento bio-guiado dos extratos de A. cearensis e L. sidoides levou ao isolamento de 12 cumarinas até o momento ${ }^{19}$, demonstrando a utilidade e praticidade deste tipo de ensaio para a bioprospecção de novos fármacos anticolinesterásicos.

A galantamina (4) é um alcalóide isolado de várias espécies vegetais da família Amaryllidaceae e mostrou-se um inibidor da AChE de ação longa, seletivo, reversível e competitivo, cujos efeitos terapêuticos permanecem mesmo após o término do tratamento 9 . $\mathrm{O}$ excelente perfil terapêutico de $\mathbf{4}$, que caracterizou um grande avanço no planejamento de fármacos para o tratamento de DA, é decorrente de seu mecanismo de ação duplo, como inibidor da AChE e como APL nos receptores nicotínicos cerebrais ${ }^{10,11}$. A galantamina (4) atua ligando-se ao sítio ativo da $\mathrm{AChE}$ cerebral e ainda estimula os receptores nicotínicos pré- e pós-sinápticos os quais podem, então, aumentar a liberação de neurotransmissores como ACh e glutamato, estimulando diretamente a função neuronal ${ }^{21}$.

Outro alcalóide isolado de Eucharis grandiflora (Amaryllidaceae), a sanguinina (9-O-desmetilgalantamina, 5), mostrou-se 10 vezes mais ativo que a própria galantamina em ensaios in vitro. A busca por outras substâncias inibidoras de AChE (IAChE) nesse gênero vegetal levou ao isolamento de outros dois derivados ativos da galantamina, a 11-hidroxigalantamina (6) e a epinorgalantamina (7). Outro padrão estrutural de alcalóides, tipo-licorina, foi isolado desse gênero, cujos constituintes mais ativos foram a oxoassoanina (8), a assoanina (9) e a pseudolicorina $(\mathbf{1 0})^{9}$.

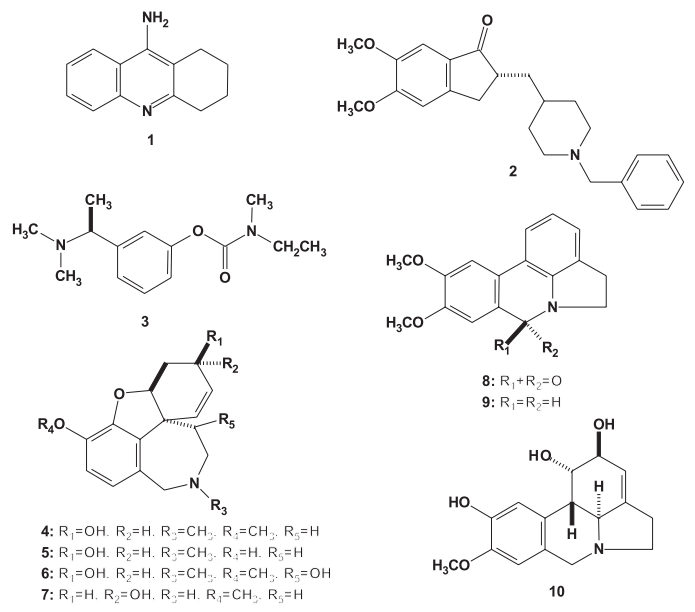

O estudo de várias espécies vegetais de uso corrente na medicina popular chinesa e do Oriente Médio levou ao isolamento de vários alcalóides ativos. Exemplo disso foi Huperzia serrata (sinonímia: Lycopodium serratum), que fornece um chá prescrito há séculos na China para o tratamento da febre e inflamação. O estudo fitoquímico dessa planta levou ao isolamento de huperzina A (11), um candidato interessante para o tratamento de desordens do SNC e epilepsia, cujo efeito diminui a morte neuronal causada por altas concentrações de glutamato. É um IAChE seletivo, muito potente e o uso sistêmico aumenta a liberação de $\mathrm{ACh}$, dopamina e norepinefrina, sendo que o aumento da concentração de ACh persiste por até $6 \mathrm{~h}$ e praticamente não possui ação sobre a butirilcolinesterase plasmática $(\mathrm{BuChE})^{22,23}$. Dessa mesma planta foi obtida a huperzina P (12), um novo alcalóide tipo-licopodium, entretanto sua atividade foi menor que aquela evidenciada para a huperzina A (11).
Os resultados obtidos com a huperzina A estimularam Orhan et $a l .{ }^{24}$ a estudarem outras 5 espécies de Lycopodium, à procura de outro metabólitos inibidores de AChE. Após uma avaliação preliminar dos extratos pelo ensaio de Ellmann ${ }^{20}$, o extrato das partes aéreas de L. clavatum foi selecionado e o fracionamento bio-guiado resultou no isolamento da $\alpha$-onocerina (12a). Os resultados da atividade anticolinesterásica demonstraram que a $\alpha$-onocerina $\left(\mathrm{IC}_{50}=5,2 \mu \mathrm{m}\right)$ foi melhor que o donepezil (2) nas concentrações de 1 e $3 \mathrm{mg} / \mathrm{mL}$ e praticamente equipotente na concentração de $5 \mathrm{mg} / \mathrm{mL}$, embora não tenha atingido a potência da galantamina em nenhuma dose testada.

Alguns alcalóides triterpênicos foram isolados de Buxus hyrcana, como a homomoenjodaramina (13) e a moenjodaramina (14), os quais mostraram-se promissores inibidores de $\mathrm{AChE}^{25}$. Desta mesma família, Buxus papillosa forneceu outros três alcalóides esteroidais inibidores seletivos de AChE: cicloprotobuxina C (15), ciclovirobuxeina A (16) e ciclomicrofilina A (17) ${ }^{26}$.
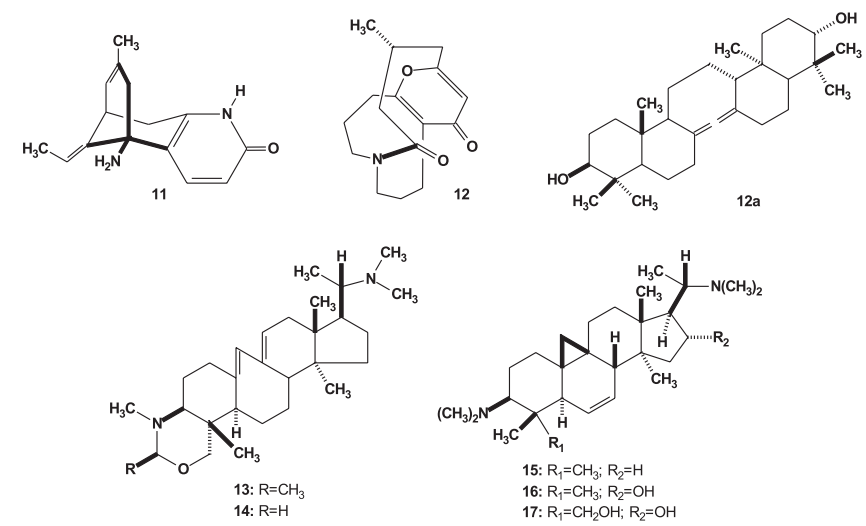

A zeatina (18), inicialmente descrita como agente indutor de crescimento de plântulas, foi isolada de Fiatoua villosa, cujo extrato metanólico havia sido selecionado após triagem para atividade inibitória de $\mathrm{AChE}^{27}$. A substância pura 18 inibiu a atividade da $\mathrm{AChE}$ de modo dose-dependente com $\mathrm{IC}_{50}$ de $1,09 \times 10^{-4} \mathrm{M}^{27}$.

Os glico-alcalóides presentes em altas concentrações na casca da batata (Solanum tuberosum L.) têm sido responsáveis por vários dos casos de intoxicação alimentar. A observação de pacientes intoxicados revelou sintomas como confusão mental, depressão e fraqueza. Estes efeitos foram atribuídos à inibição da AChE pela $\alpha$ solanina (19) e $\alpha$-chaconina (20), que correspondem a $95 \%$ dos glicoalcalóides presentes em $S$. tuberosum $^{28}$.
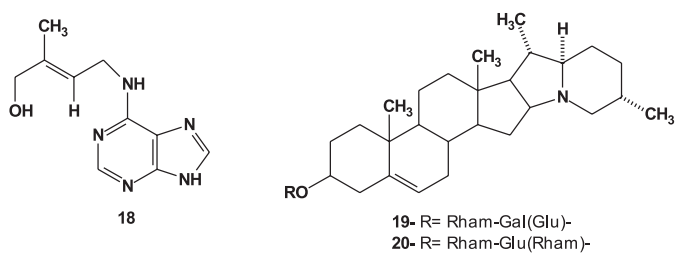

Culturas de microorganismos, especialmente de fungos de diversas famílias e gêneros, vêm sendo sistematicamente estudadas como importantes fontes na busca por fármacos úteis no tratamento de doenças graves como câncer, malária e infecções bacterianas, dentre outras.

Buscando novos candidatos a fármacos capazes de re-estabelecer o sistema de neurotransmissão colinérgica, Otoguro, Kuno et al..$^{29-31}$ descobriram novos inibidores de AChE através da triagem sistemática de produtos naturais produzidos por fungos, i.e. arisugacinas. A partir das culturas WK-4164 e FO-4259 de fungos do 
solo foram obtidas a ciclofostina (21), a arisugacina A (22) e B (23), além das já conhecidas territrems B (24) e C (25) e a ciclopenina (26). Dentre estes derivados, as arisugacinas $A\left(\mathrm{IC}_{50}=1,0 \mathrm{nM}\right)$ e B $\left(\mathrm{IC}_{50}=25,8 \mathrm{nM}\right)$ não inibiram a BuChE, mesmo em concentrações 20.000 vezes superiores à concentração de inibição de $50 \%$ da atividade da AChE, demonstrando excelente perfil de seletividade.

Já os derivados territrems B e C foram muito menos seletivos, apesar de apresentarem bom perfil de inibição de $\mathrm{AChE}$, i.e. $\mathrm{IC}_{50}=$ 7,6 $\mathrm{nM}$ e $6,8 \mathrm{nM}$, respectivamente. A ciclopenina (26) foi a substância menos ativa desta família como inibidor de $\mathrm{AChE}\left(\mathrm{IC}_{50}=\right.$ $2040 \mathrm{nM}$ ); entretanto, foi bastante seletiva, não inibindo a BuChE em concentrações até 2000 vezes maiores que sua $\mathrm{IC}_{50}$. Apesar de muito potente $\left(\mathrm{IC}_{50}=1,3 \mathrm{nM}\right)$, a ciclofostina (21) foi a substância que apresentou menor seletividade, passando a inibir a BuChE em doses superiores a 35 vezes sua $\mathrm{IC}_{50}{ }^{29-32}$

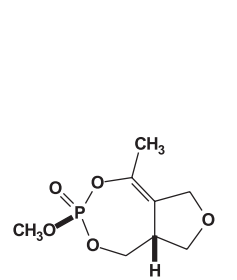

21

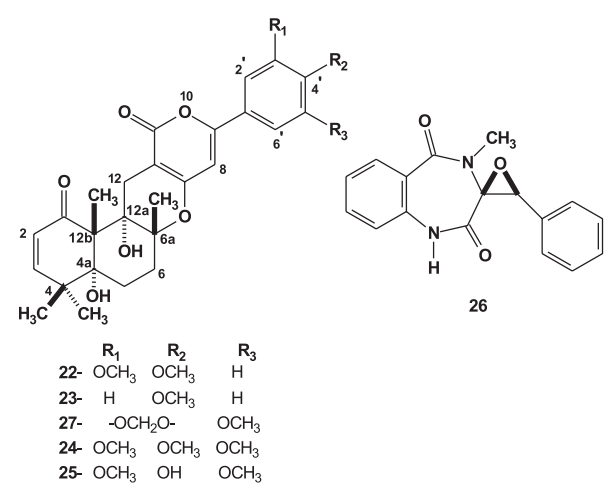

As territrems A (27), B (24) e C (25) já haviam sido isoladas de culturas de Aspergillus terreus e apesar da baixa seletividade demonstrada pelos estudos de Otoguro et $a{ }^{31}{ }^{31}$, a territrem B foi cerca de 20 vezes mais potente que a neostigmina na inibição da AChE. Estes resultados estimularam Peng ${ }^{33}$ a preparar os derivados dos territrems 28-33 para estudo da relação estrutura química-atividade biológica. A avaliação da inibição da atividade enzimática pelo método de Ellmann ${ }^{20}$ não revelou aumento de potência para nenhum dos derivados semi-sintéticos dos territrems, entretanto permitiu o reconhecimento da ligação dupla em C-2, da carbonila em C-1 e da unidade $\delta$-pirona intacta como os grupos farmacofóricos imprescindíveis para a atividade anticolinesterásica desta série de compostos.

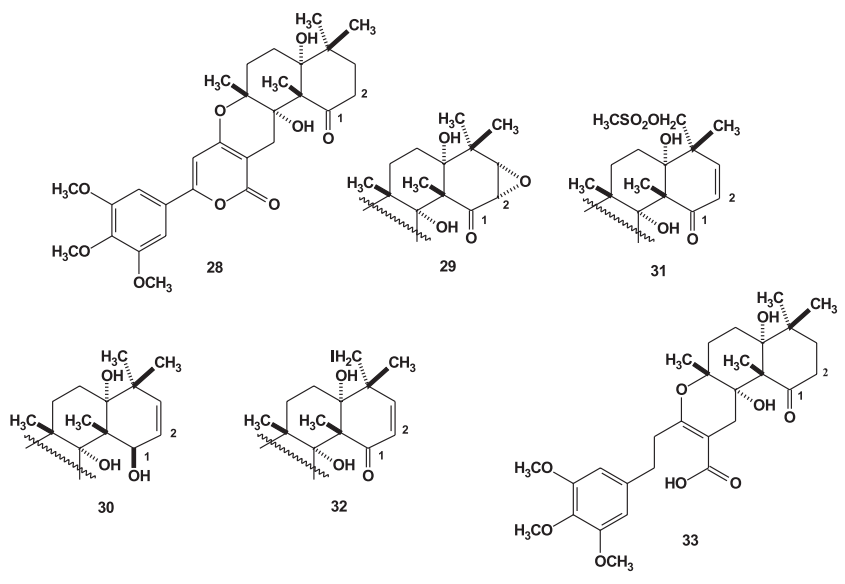

$\mathrm{O}$ interesse por inibidores de $\mathrm{AChE}$ em metabólitos microbiais monitorados pelo ensaio de Ellmann ${ }^{20}$ levou Kim et al.$^{34}$ a investigarem as culturas de um novo fungo, o Penicillium citrinum 90648. Do fermentado sólido deste microorganismo foram isolados os diaste- reoisômeros quinolactacina A1 (34) e quinolactacina A2 (35). A avaliação da atividade anticolinesterásica destas substâncias revelou que 35 apresentou atividade inibitória da AChE 14 vezes superior a seu diastereoisômero 34. Seu efeito foi dose-dependente, apresentando uma $\mathrm{IC}_{50}=19.8 \mu \mathrm{M}$, enquanto que a $\mathrm{IC}_{50}$ de $\mathbf{3 5}$ foi de apenas $280 \mu \mathrm{M}$. Além disso, o diastereoisômero bioativo 35 mostrou atividade inibitória competitiva com o substrato e seletiva para a AChE versus butirilcolinesterase $\left(\mathrm{BuChE}, \mathrm{IC}_{50}=650 \mu \mathrm{M}\right)$, utilizando-se em todos os ensaios a tacrina como padrão positivo $\left(\mathrm{IC}_{50 \mathrm{BuChE}}=0.006 \mu \mathrm{M}\right.$, $\left.\mathrm{IC}_{50 \mathrm{AChE}}=0,12 \mu \mathrm{M}\right)^{34}$.
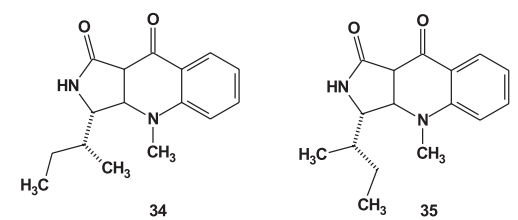

Pelo exposto, torna-se evidente a necessidade de se explorar os produtos naturais oriundos da grande biodiversidade brasileira, como fonte de inspiração para o planejamento racional de novos candidatos a fármacos potentes e seletivos e com baixo perfil de toxicidade, que permitam o controle da evolução da doença de Alzheimer.

\section{AGRADECIMENTOS}

Os autores agradecem a FAPESP, FINEP, CAPES, FAPERJ, FUJB e ao CNPq pelo apoio financeiro e bolsas concedidas.

\section{REFERÊNCIAS}

1. Francis, P. T.; Palmer, A. M.; Snape, M.; Wilcock, G. K.; J. Neurol. Neurosurg. Psychiatry 1999, 66, 137.

2. www.biostat.wustl.edu/alzheimer/, acessada Maio 2003.

3. Michaelis, M. L.; J. Pharm. Exper. Ther. 2003, 304, 897.

4. Gooch, M. D.; Stennett, D. J.; Am. J. Health Syst. Pharm. 1996, 53, 1545

5. Rufani, M.; Filocamo, L.; Lappa, S.; Maggi, A.; Drugs in the Future 1997, $22,397$.

6. Tabarrini, O.; Cecchetti, V.; Temperini, A.; Filipponi, E.; Lamperti, M. G.; Fravolini, A.; Bioorg. Med. Chem. 2001, 9, 2921.

7. www.bimcore.emory.edu/.../Mrobbin/ bioweb/ach/text.html, acessada em Maio 2003.

8. http://learn.usc.edu/courses/PHAR545, acessada em Março 2003.

9. López, S.; Bastida, J.; Viladomat, F.; Codina, C.; Life Sci. 2002, 71, 2521.

10. Maelicke, A.; Schrattenholz, A.; Samochocki, M.; Radina, M.; Albuquerque, E. X.; Behavioural Brain Res. 2000, 113, 199.

11. Quik, M.; Jeyarasasingam, G.; Eur. J. Pharmacol. 2000, 393, 223.

12. Greenlee, W.; Clader, J.; Asberom, T.; McCombie, S.; Ford, J.; Guzik, H.; Kozlowski, J.; Li, S.; Liu, C.; Lowe, D.; Vice, S.; Zhao, H.; Zhou, G.; Billard, W.; Binch, H.; Crosby, R.; Duffy, R.; Lachowicz, J.; Coffin, V.; Watkins, R.; Ruperto, V.; Strader, C.; Taylor, L.; Cox, K.; Il Farmaco 2001, 56, 247.

13. Maelicke, A.; Albuquerque, E. X.; Eur. J. Pharmacol. 2000, 393, 165.

14. Maelicke, A.; Samochocki, M.; Jostock, R.; Fehrenbacher, A.; Ludwig, J.; Albuquerque, E. X.; Zerlin, M.; Biol. Psych. 2001, 49, 279.

15. Gold, P. E.; Cahill, L.; Wenk, G.L.; Psych. Sci. Publ. Int. 2002, $3,2$.

16. Hostettmann, K.; Queiroz, E. F.; Vieira, P. C.; Princípios Ativos de Plantas Superiores, $1^{\mathrm{a}}$. ed., EdUFSCar: São Carlos, 2003.

17. Marston, A.; Kissiling, J.; Hostettmann, K.A.; Phytochem. Anal. 2002, 13, 51.

18. Rhee, I. K.; van der Meent, M.; Ingkaninan, K.; Verpoorte, R.; J. Chromatogr., A 2001, 915, 217.

19. Trevisan, M. T. S.; Macedo, F. V. V.; van de Meent, M.; Rhee, I. K.; Verpoorte, R.; Quim. Nova 2003, 26, 301.

20. Ellmann, G. L.; Biochem. Pharmacol. 1961, 7, 88.

21. Fennel, C. W.; van Staden, J.; J. Ethnopharmacol. 2001, 78, 15.

22. Chang, J.; Biochem. Pharmacol. 2000, 59, 211.

23. Rajendran, V.; Saxena, A.; Doctor, B. P.; Kozikowski, A. P.; Bioorg. Med. Chem. 2002, 10, 599.

24. Orhan, I.; Terzioglu, S.; Sener, B.; Planta Med. 2003, 69, 265. 
25. Ur-Rahman, A.; Choudhary, M. I.; Pure Appl. Chem. 1999, 71, 1079.

26. Ur-Rahman, A.; Parveen, S.; Khalid, A.; Farroq, A.; Choudhary, M. I.; Phytochemistry 2001, 58, 963.

27. Heo, H-J.; Hong, S-C.; Cho, H-Y.; Hong, B.; Kim, H-K.; Kim, E-K.; Shim, D-H.; Mol. Cell 2002, 13, 113.

28. Smith, D. B.; Roddick, J. G.; Jones, J. L.; Trends Food Sci. Technol. 1996, $7,126$.

29. Kuno, F.; Otoguro, K.; Shiomi, K.; Iwai, Y.; Omura, S.; J. Antibiot. 1996, $49,742$.
30. Kuno, F.; Shiomi, K.; Otoguro, K.; Sunazuka, T.; Omura, S.; J. Antibiot. 1996, 49, 748.

31. Otoguro, K.; Kuno, F.; Omura, S.; Pharmacol. Ther. 1997, 76, 45.

32. Shiomi, K.; Tomoda, H.; Otoguro, K.; Omura, S.; Pure Appl. Chem. 1999, 71,1059

33. Peng, F-C.; J. Nat. Prod. 1995, 58, 857.

34. Kim, W-G.; Song, N-K.; Yoo, I-D.; J. Antibiot. 2001, 54, 831. 